\title{
Mechanisms of improved glycaemic control after Roux-en-Y gastric bypass
}

\author{
C. Dirksen • N. B. Jørgensen • K. N. Bojsen-Møller • \\ S. H. Jacobsen • D. L. Hansen • D. Worm • J. J. Holst • \\ S. Madsbad
}

Received: 8 December 2011 / Accepted: 21 February 2012 /Published online: 27 April 2012

(C) Springer-Verlag 2012

\begin{abstract}
Roux-en-Y gastric bypass (RYGB) greatly improves glycaemic control in morbidly obese patients with type 2 diabetes, in many even before significant weight loss. Understanding the responsible mechanisms may contribute to our knowledge of the pathophysiology of type 2 diabetes and help identify new drug targets or improve surgical techniques. This review summarises the present knowledge based on pathophysiological studies published during the last decade. Taken together, two main mechanisms seem to be responsible for the early improvement in glycaemic control after RYGB: (1) an increase in hepatic insulin sensitivity induced, at least in part, by energy restriction and (2) improved beta cell function associated with an exaggerated postprandial glucagon-like peptide 1 secretion owing to the altered transit of nutrients. Later a weight loss induced improvement in peripheral insulin sensitivity follows.
\end{abstract}

C. Dirksen $(\bowtie) \cdot$ N. B. Jørgensen • K. N. Bojsen-Møller •

S. H. Jacobsen • D. L. Hansen · D. Worm • S. Madsbad

Department of Endocrinology 541, Hvidovre Hospital,

University of Copenhagen,

Kettegaard Allé 30,

2650 Hvidovre, Denmark

e-mail: carsten.dirksen@hvh.regionh.dk

C. Dirksen • N. B. Jørgensen • K. N. Bojsen-Møller •

S. H. Jacobsen $\cdot$ J. J. Holst

Novo Nordisk Foundation Centre for Basic Metabolic Research,

The Panum Institute, University of Copenhagen,

Copenhagen N, Denmark

N. B. Jørgensen · J. J. Holst

Department of Biomedical Sciences, The Panum Institute,

University of Copenhagen,

Copenhagen N, Denmark
Keywords Bariatric surgery $\cdot$ Beta cell function · Incretin hormones $\cdot$ Insulin sensitivity $\cdot$ Obesity $\cdot$ Review . Roux-en-Y gastric bypass · Type 2 diabetes mellitus

$\begin{array}{ll}\text { Abbreviations } \\ \text { AIRg } & \begin{array}{l}\text { Acute insulin response to glucose } \\ \text { Disposition index }\end{array} \\ \text { DI } & \begin{array}{l}\text { Frequently sampled intravenous } \\ \text { glucose tolerance test }\end{array} \\ \text { GIP } & \begin{array}{l}\text { Glucose-dependent insulinotropic peptide } \\ \text { GLP-1 }\end{array} \\ \text { Glucagon-like peptide 1 } \\ \text { HEC } & \text { Hyperinsulinaemic-euglycaemic clamp } \\ \text { HGP } & \text { Hepatic glucose production } \\ \text { HOMA-IR } & \text { HOMA of insulin resistance } \\ \text { IGI } & \text { Insulinogenic index } \\ \text { ITT } & \text { Insulin tolerance test } \\ \text { MMT } & \text { Mixed meal test } \\ \text { NGT } & \text { Normal glucose tolerance } \\ \text { PYY } & \text { Peptide YY Y-36 } \\ \text { RYGB } & \text { Roux-en-Y gastric bypass }\end{array}$

\section{Introduction}

The prevalence of type 2 diabetes has increased dramatically along with the worldwide obesity pandemic. Conventional strategies to treat type 2 diabetes including lifestyle intervention and pharmacotherapy have been somewhat successful in delaying the development of cardiovascular disease and late diabetes complications through improved glycaemic control and treatment of hypertension and dyslipidaemia, but they require good treatment compliance, regular clinical check-ups and, eventually, lifelong medication. During the last decade it has been recognised that a prolonged 
improvement in glycaemic control without the need for a glucose-lowering medication can be achieved in morbidly obese patients with type 2 diabetes using Roux-en-Y gastric bypass (RYGB) surgery or related bariatric procedures $[1$, 2]. Interestingly, the improvement in glycaemic control after RYGB often occurs within days of the surgery, before any significant weight loss [3], and even in patients with only mild obesity [4]. This points to a role for weight lossindependent mechanisms possibly related to the changes in gastrointestinal anatomy and transit of nutrients.

In this review we discuss potential mechanisms for the improved glycaemic control after RYGB, the most widespread bariatric surgical procedure at present. We focus on the effects of the operation on insulin resistance and beta cell dysfunction, as well as on the adipose tissue, the alpha cells and the secretion of incretin hormones and other gut hormones. The form of a narrative review has been chosen to give a wide and comprehensive coverage of relevant mechanisms. The reviewed studies were identified by electronic and manual literature searches, including hand-search of the reference lists of identified papers. Studies were considered relevant if they reported the impact of RYGB surgery on the pathophysiological defects of type 2 diabetes in morbidly obese (BMI $\geq 35 \mathrm{~kg} / \mathrm{m}^{2}$ ) adults (age $\geq 18$ years). Please refer to the text box 'Physiological indices' for an overview of the indices mentioned in the text.

\section{Roux-en-Y gastric bypass}

RYGB is a bariatric surgical procedure that involves sectioning of the jejunum $50-100 \mathrm{~cm}$ from the pylorus, anastomosis between the distal loop of the severed jejunum (the alimentary limb) to a small gastric pouch created around the oesophagus, and anastomosis between the proximal loop of the severed jejunum (the secretory limb) with the small intestine at a site that is now $150-200 \mathrm{~cm}$ distal relative to the position of the pylorus before the RYGB. Thus, nutrients bypass the major part of the stomach, the duodenum and the upper part of the jejunum (Fig. 1). The procedure is recommended in morbidly obese patients (BMI $\geq 40 \mathrm{~kg} / \mathrm{m}^{2}$ or $\geq 35 \mathrm{~kg} / \mathrm{m}^{2}$ in the presence of comorbidities) who have been unable to lose weight with conventional treatment strategies including diet and pharmacotherapy [5]. The weight loss induced by the surgery is, on average, $25-30 \%$ of total body weight, attaining a nadir $12-18$ months postoperatively, and is maintained for at least 10 years postoperatively in most patients [6]. Individuals who undergo the operation show a significant reduction in morbidity and mortality compared with non-operated obese individuals [6], primarily due to the beneficial effects of the procedure on the comorbidities of obesity. Today, most surgeons use a laparoscopic technique and the perioperative mortality is as low as $0.3 \%[7]$.

\section{The remission of type 2 diabetes mellitus after RYGB}

In 1995 Pories et al [3] reported that among 146 morbidly obese patients with type 2 diabetes who underwent gastric bypass, 121 (83\%) experienced a rapid and prolonged postoperative normalisation of plasma glucose levels without the need for glucose-lowering medication. This remarkable observation was later replicated in several other studies and

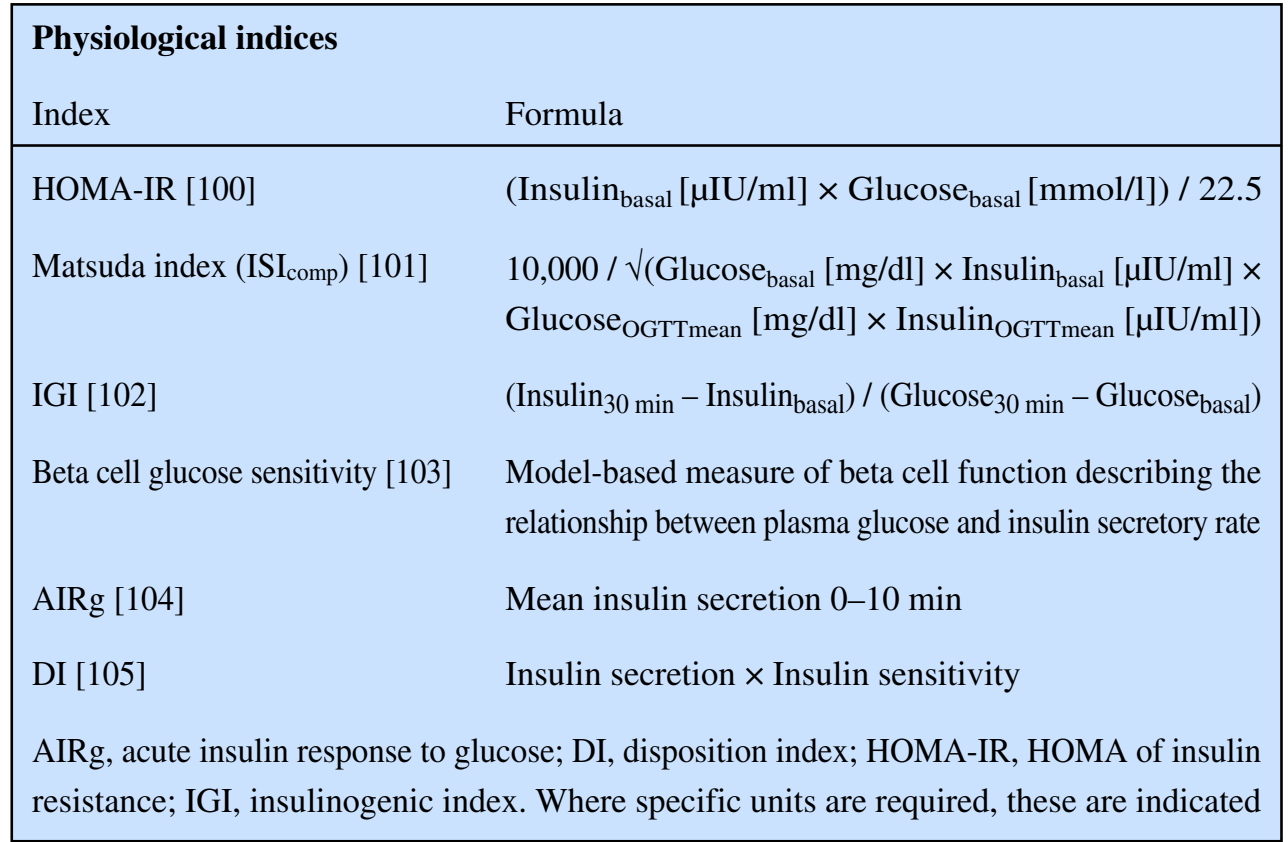




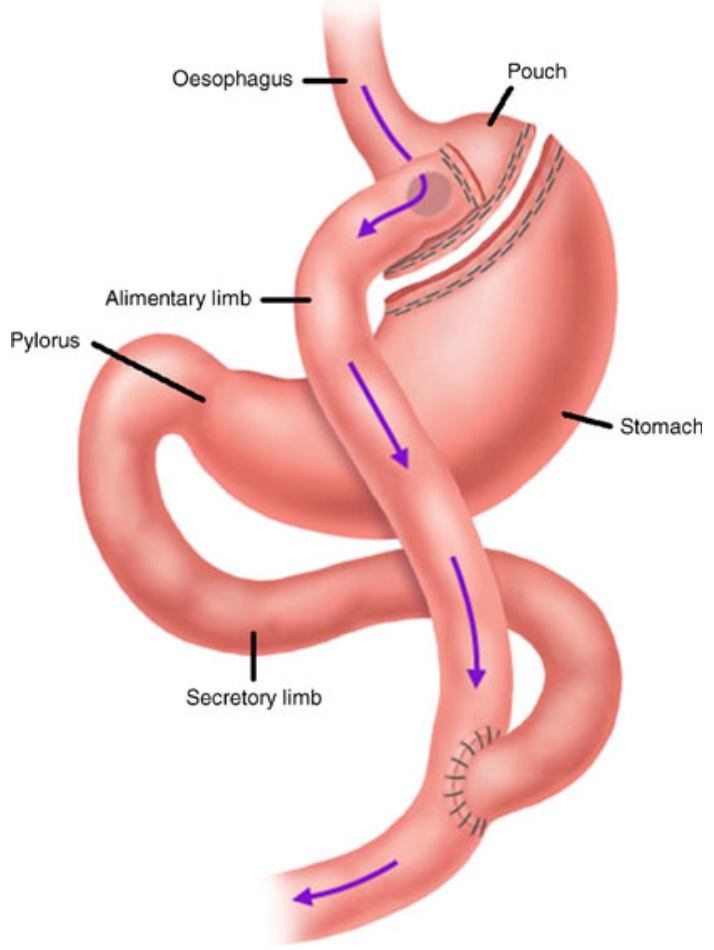

Fig. 1 The gastrointestinal anatomy after Roux-en-Y gastric bypass

confirmed in a large meta-analysis of 621 studies, including nearly 5,000 patients with type 2 diabetes, which reported that diabetes remission was seen in $80.3 \%$ after RYGB [8]. However, in a recent study of 160 patients who underwent RYGB, only $40.6 \%$ achieved complete diabetes remission as defined by the criteria from the consensus report from 2009 [1, 9]. Thus, the rate of diabetes remission after RYGB strongly depends on the definition of remission as well as on the severity of the disease, with $\mathrm{HbA}_{1 \mathrm{c}}$, insulin sensitivity and beta cell function being worse in non-remitters prior to surgery [10]. For these reasons this review focuses on RYGB as a tool to improve glycaemic control rather than as a means to achieve diabetes remission.

\section{Insulin sensitivity and RYGB}

The gold standard technique of measuring insulin sensitivity is the hyperinsulinaemic-euglycaemic clamp (HEC), which primarily measures insulin sensitivity in muscle but can also be combined with isotope-labelled glucose to assess hepatic glucose production (HGP) and, thereby, hepatic insulin sensitivity. Other methods for assessing insulin sensitivity include the frequently sampled intravenous glucose tolerance test (FSIGT), the insulin tolerance test (ITT) and indices derived from a standard $75 \mathrm{~g}$ OGTT, e.g. the Matsuda index. However, the most frequently used measure of insulin resistance is the HOMA formula (HOMA-IR), which is primarily a surrogate index of hepatic insulin resistance.
Results from oral tests The effect of RYGB on insulin sensitivity has been assessed in two studies using the Matsuda index based on a liquid mixed meal test (MMT) [11, 12] and in one study using mathematical modeling based on an OGTT [10]. All three studies reported significant increases in insulin sensitivity between 4 weeks and 1 year postoperatively, and in one of the studies the increase was proportional to the decrease in BMI [10]. However, the measurement of insulin sensitivity based on oral tests after RYGB has not been validated. This is important because RYGB dramatically affects the absorption rate of glucose with a more rapid uptake after surgery $[13,14]$, which may affect calculation of the indices. These limitations underscore the need for validation of oral tests in individuals post RYGB, as recently carried out for gastric banding, another bariatric procedure [15].

Results from intravenous tests Not surprisingly, a weight loss of $10-20 \mathrm{~kg} / \mathrm{m}^{2} 6-12$ months after RYGB has been demonstrated to significantly improve peripheral insulin sensitivity measured by the HEC in obese patients with normal glucose tolerance (NGT) [16-22] and type 2 diabetes $[20,23,24]$. Similar results have also been found using other techniques, including FSIGT and ITT [25-30]. Furthermore, reductions in HGP or hepatic insulin resistance index have been found in four glucose tracer studies performed 6-12 months after RYGB [18, 20, 21, 31]. Whether improved insulin sensitivity also plays a role in the early improvement of glycaemic control after RYGB, which is independent of weight loss, is unclear. Several studies have shown a significant reduction in HOMA-IR within the first month after RYGB in patients with NGT and type 2 diabetes $[11,19,26,27,32-38]$, with 4 days postoperatively being the earliest record of a significant decrease in HOMA-IR [32]. In contrast, 2-4 weeks after RYGB, studies involving HEC to measure insulin sensitivity did not find any improvement in peripheral insulin sensitivity, despite significant weight loss and a significant decrease in HOMA-IR $[19,20,39,40]$. This discrepancy between HOMA-IR and the HEC may reflect differential effects of RYGB on peripheral and hepatic insulin sensitivity during the early postoperative period. In support of this, a recent HEC study using glucose tracer reported decreased HGP and improved hepatic insulin sensitivity without changes in peripheral insulin sensitivity in 17 patients with type 2 diabetes and 23 individuals with NGT, 1 month after RYGB [40]. However, a similar study showed no major changes on either basal HGP or peripheral insulin sensitivity 2-3 weeks after RYGB [20].

Interestingly, a similar pattern of concomitant decreases in fasting glucose and insulin, i.e. reduced HOMA-IR without changes in peripheral insulin sensitivity, has been reported after energy restriction. Kirk et al found a $40 \%$ 
decrease in HOMA-IR without changes in peripheral insulin sensitivity after $48 \mathrm{~h}$ of low-carbohydrate energy restriction and a limited weight loss of $2 \mathrm{~kg}$ in obese individuals with NGT [41]. Additionally, the authors found a decrease in basal HGP, an increase in hepatic insulin sensitivity and a $20 \%$ reduction in intrahepatic lipid content. Continuation of the energy restriction for 11 weeks did not result in any further improvements in hepatic insulin sensitivity, but produced a significant increase in peripheral insulin sensitivity [41]. Similar findings, including reduced fasting glucose and insulin levels, reduced basal HGP, increased hepatic insulin sensitivity and reduced intrahepatic lipid content, have recently been reported in 11 obese patients with type 2 diabetes after 1 week of energy restriction [42]. The changes persisted at 4 and 8 weeks' follow-up, and peripheral insulin sensitivity did not change throughout the study despite a $15.3 \mathrm{~kg}$ weight loss after 8 weeks [42]. Thus, improved hepatic insulin sensitivity induced by postoperative energy restriction may explain the isolated reduction in HOMA-IR seen early after RYGB. In two studies that directly compared RYGB with energy restriction, a comparable decrease in HOMA-IR was found in both intervention groups [32, 33]. In contrast, other investigators have found greater decreases in HOMA-IR after RYGB than after energy restriction or gastric restrictive surgery [11, 35-37]. Foo et al used an interesting paired experimental design in which each volunteer underwent 6 days of energy restriction before and immediately after RYGB. They found a larger decrease in HOMA-IR after the combined RYGB and energy restriction, than during the preoperative energy restriction period [37]. Thus, further studies are needed to evaluate the differential effects of RYGB on peripheral and hepatic insulin sensitivity and to clarify whether the changes in gastrointestinal anatomy after RYGB cause additional improvements in insulin sensitivity independent of energy restriction.

\section{Hepatic insulin sensitivity improves immediately after RYGB in response to the energy restriction, whereas peripheral insulin sensitivity is improved later in response to the postoperative weight loss}

\section{Islet cell dysfunction and RYGB}

An important distinction should be made between intravenous and oral tests when measuring beta cell function. Intravenous tests address 'intrinsic' regulation of insulin secretion, while oral tests combine 'intrinsic' and 'extrinsic' regulation, i.e. they include the potentiating effects of the hormonal and neural responses elicited by meal ingestion (the entero-insular axis). The most frequently applied intravenous tests include the FSIGT, the hyperglycaemic glucose clamp and the arginine test, while oral tests can be performed using an OGTT or MMT. Since insulin secretion during any of these tests is, in part, determined by the prevailing insulin sensitivity, beta cell function usually is expressed as the disposition index (DI).

Results from oral tests Insulin secretion in response to an oral stimulus is significantly altered after RYGB, with an earlier and exaggerated postprandial rise in insulin concentration that reaches a higher peak level than that achieved before RYGB [11, 13, 14, 33, 35, 38, 43-52]. However, the total postprandial AUC for insulin is unchanged or even decreased, consistent with the improved insulin sensitivity and a more rapid return of insulin concentrations to fasting levels [14, 19, 33, 38, 43, 44]. Recently, two studies from the same research group described no change, or even a significant decrease, in peak insulin concentrations after RYGB [32, 53]. However, these contradictory findings may be explained by the lack of blood sampling in the first $60 \mathrm{~min}$ after the end of the meal, which is the time period when insulin levels usually peak [54]. In a study of ten patients with type 2 diabetes, early insulin secretion during an oral stimulus, measured by the insulinogenic index (IGI), was significantly increased 30 and 90 days after RYGB, but unchanged at 7 days postoperatively [38]. A significant increase in IGI, irrespective of glucose tolerance, has also been reported by other investigators 4-6 weeks after RYGB $[11,55]$, but not after gastric restrictive surgery [11]. One year postoperatively, the increase in IGI seems to level off, probably in response to the increase in peripheral insulin sensitivity $[51,55]$. Accordingly, in the only study to adjust IGI for changes in insulin sensitivity, there was a nonsignificant increase in the unadjusted IGI 1 year after RYGB, and a significant increase in DI [51]. Also, beta cell glucose sensitivity in response to both an OGTT and an MMT has been shown to increase early after RYGB [10, $11,52]$ but does not fully normalise even 3-12 months postoperatively in patients with type 2 diabetes $[10,52]$.

Results from intravenous tests Insulin secretion after RYGB in response to an intravenous stimulus has been reported in five studies, four of which used the FSIGT [25, 30, 52, 55, 56] and one the more laborious hyperglycaemic clamp [11]. The FSIGT studies found a gradual increase in first phase insulin secretion (acute insulin response to glucose; AIRg) (see text box 'Physiological indices') in patients with type 2 diabetes during the first 12 months after RYGB, while AIRg declined in individuals with NGT $[25,30,52,55,56]$. Accordingly, large significant increases in DI (8.5- to 83fold) were observed in patients with type 2 diabetes, while patients with NGT experienced no change in DI $[25,30,55$, 56]. The results from the hyperglycaemic clamp did not show any change in AIRg or DI during the first 
postoperative month, the latter despite a significant doubling in insulin sensitivity, suggesting a lack of statistical power [11]. Second phase insulin secretion appears to decline postoperatively, with changes apparent within the first month $[11,30]$.

Postprandial insulin secretion is altered immediately after RYGB - secretion is more rapid and exaggerated, but is shorter lasting. Intrinsic beta cell function gradually recovers in patients with type 2 diabetes and is unchanged in individuals with NGT

Alpha cell function In a study including 12 volunteers with NGT who underwent an MMT before and at various times after RYGB, fasting glucagon concentrations were unchanged [14]. Postprandial glucagon concentrations were increased significantly 3 days and 2 months after surgery, but returned to preoperative levels 1 year postoperatively [14]. A similar postprandial increase in plasma glucagon without changes in fasting plasma glucagon has been reported in patients with type 2 diabetes 1 month after surgery [33]. This temporary increase in postprandial glucagon levels during the first months after surgery is a paradoxical increase given the concomitant decrease in plasma glucose and increase in glucagon-like peptide 1 (GLP-1) secretion, but may reflect biologically inactive proglucagon forms derived from the gut that interfere with glucagon assays [57]. Taken together, the available results suggest that changes in circulating glucagon do not contribute to the improvements in glucose metabolism observed after RYGB.

\section{Gut hormones and RYGB}

Changes in the fasting and postprandial secretion of gutderived hormones from the enteroendocrine cells located in the gut epithelium, possibly resulting from the altered postoperative nutrient transit, have been suggested as potential mechanisms for the improvement in glycaemic control after RYGB [3, 58]. A large number of studies have subsequently supported this hypothesis by demonstrating extensive alterations in the release of hormones that regulate glucose homeostasis and appetite [59].

Incretin hormones The large number of studies that have examined changes in the release of incretin hormones after RYGB consistently find that fasting levels of GLP-1 are unchanged, whereas postprandial secretion increases by several fold [11, 13, 14, 21, 32, 36, 38, 43, 44, 46, 47, 50, $52,60,61]$. Fasting levels of glucose-dependent insulinotropic peptide (GIP) are also unchanged, but reports as to the changes in postprandial release have been more inconsistent, with some studies finding an increase [33, 46] and others no change, or even a decline, in GIP secretion $[11,13,14,47]$. These results are consistent with the change in gastrointestinal anatomy induced by the surgery, whereby nutrients bypass the proximal part of the small intestine, where most of the GIP-producing $\mathrm{K}$ cells are located, and are delivered directly into the distal small intestine, which has a high density of GLP-1-producing L cells. The inconsistent findings in GIP secretion are likely to reflect differences in the length of the limbs of the Roux anastomosis, with shorter limbs possibly being associated with higher GIP responses.

The incretin effect, i.e. greater insulin secretion in response to an oral stimulus than to an isoglycaemic intravenous stimulus, has been further investigated in patients with type 2 diabetes before and 4 weeks after surgery [44]. There was a fivefold increase in the incretin effect after RYGB and, moreover, the postoperative incretin effect did not differ statistically from that of unoperated matched controls. In another study by the same authors, similar changes in incretin effect were found in a group of patients with type 2 diabetes undergoing RYGB, but not in a matched group of patients with type 2 diabetes who achieved a comparable diet-induced weight loss [33]. These observations seem to confirm the increased insulinotropic action of GLP-1 in the postprandial period after RYGB.

Further evidence for the role of GLP-1 after RYGB has recently been provided by a study in which an MMT was performed during a hyperglycaemic clamp with and without infusion of the GLP-1 receptor antagonist exendin 9-39 in RYGB-operated participants and controls [62]. As expected, insulin secretion in response to the meal was elevated in the RYGB operated group compared with the control subjects, but was reduced to about half during blockade of GLP-1 by exendin 9-39.

The importance of the post-RYGB gastrointestinal anatomy on glucose metabolism and the release of gut hormones has been demonstrated in two case reports that examined the effect of peroral feeding vs gastroduodenal feeding in RYGB-operated patients with a gastrostomy catheter inserted in the gastric remnant $[48,49]$. In both reports, an MMT was performed on two consecutive days. On the peroral day, with nutrients passing through the gastric bypass pathway, typical postoperative exaggerated insulin and GLP-1 responses were found, while on the gastroduodenal day, with nutrients passing through the excluded pathway, insulin and GLP-1 responses mimicked those seen preoperatively. Hence, the postoperative changes in insulin and gut hormone secretion are closely related to the changes in gastrointestinal nutrient transit, possibly resulting from a more rapid delivery of nutrients to the distal parts of the small intestine, as implicated by studies of paracetamol absorption before and after RYGB [14, 63]. 
Appetite-regulating gut hormones Gut hormones also play a role in appetite regulation, with anorexigenic hormones such as GLP-1, peptide YY $3-36$ (PYY), oxyntomodulin, and cholecystokinin being released postprandially, in addition to increases in levels of ghrelin, an orexigenic hormone, preprandially. Like GLP-1, PYY is released from the intestinal L cells and levels of PPY are elevated postprandially after RYGB [13, 45, 50, 63, 64]. Levels of oxyntomodulin, another L cell product, have been reported to be elevated postoperatively [65], but the reported concentrations of oxyntomodulin were much higher than those of other $\mathrm{L}$ cell products (glicentin, GLP-1 and GLP-2), throwing doubt on the accuracy of the assays, given that oxyntomodulin is a product of the intestinal processing of proglucagon [66]. Nevertheless, significantly increased postprandial levels of enteroglucagon have been found after RYGB [14], 30-40\% of which may be oxyntomodulin. In the only available study on cholecystokinin, fasting cholecystokinin concentrations did not change postoperatively in ten patients 3 weeks after RYGB [58]. In contrast to the increase in ghrelin levels observed after diet-induced weight loss, levels were initially reported to be markedly reduced after RYGB [67], but subsequent studies have not been able to reproduce this finding, with most studies reporting modest decreases in fasting and postprandial ghrelin levels during the first 612 months after RYGB [59]. However, recent studies have found that ghrelin levels return to preoperative values, or even increase, years after RYGB [14, 68].

Postprandial GLP-1 release is exaggerated after RYGB
and potentiates postprandial insulin secretion. The increased
release of GLP-1, PYY and possibly other anorexigenic
hormones, such as oxyntomodulin and cholecystokinin,
may contribute to the postoperative weight loss and thereby
indirectly to improved insulin sensitivity

\section{Adipose tissue and RYGB}

The massive weight loss after RYGB comprises a $50 \%$ reduction in whole body fat mass including a $60 \%$ decrease in visceral adipose tissue as assessed 12 months after the procedure by dual-energy X-ray absorptiometry and computer tomography, respectively. During the same time period, lean body mass is reduced by $15-20 \%$ [69-71].

NEFA Fasting NEFA concentrations have been reported to be elevated 1 month after RYGB in patients with various degrees of glucose tolerance [20, 34, 39]. However, at 3 months postoperatively, NEFA levels have already returned to preoperative values and do not show any further alterations at 6 and 12 months follow-up [20, 34, 72]. Postprandial NEFA concentrations 2-3 years after RYGB are similar to those of matched controls during an $8 \mathrm{~h}$ fatty meal test [73]. Using the HEC with a glycerol tracer and indirect calorimetry, a large increase in lipolysis and lipid oxidation rates has also been shown during the first 2-3 weeks after RYGB, with normalisation at the 1 year follow-up [20]. In another study, insulin-mediated suppression of NEFA in RYGB-operated patients was comparable to that in lean controls and was significantly greater than that in obese controls more than 1 year postoperatively [74].

Adipokines Changes in adipokines after RYGB are primarily characterised by a decrease in leptin [14, 34, 39, 58, 73, 75] and an increase in adiponectin levels [75-77] that appear to be associated with the degree of postoperative weight loss, and thus may reflect the amount of remaining adipose tissue. Furthermore, levels of IL-6 and visfatin are reduced postoperatively [34] and resistin levels are unchanged [78]. The decreasing plasma leptin levels and the increasing plasma adiponectin levels that occur after surgery favour an anti-inflammatory state and reduced levels of insulin resistance [14, 26].

In summary, body fat content, including visceral fat, is substantially reduced as part of the large postoperative weight loss. NEFA levels are increased early after surgery, probably reflecting fat mobilisation during the fast weight loss, but return to normal levels when the weight loss levels off. The concentration of leptin is reduced along with the reduction in adipose tissue, while adiponectin levels increase.

\section{Bile acids and RYGB}

A study comparing non-diabetic post-RYGB patients with morbidly obese and overweight controls found a more than twofold elevation of fasting bile acids in the post-RYGB group [79]. Moreover, bile acid concentrations were correlated with key metabolic variables, including inverse relationships with $2 \mathrm{~h}$ post-meal glucose, triacylglycerols, and thyroid-stimulating hormone levels, while correlations with adiponectin and peak postprandial GLP-1 concentrations were positive. The authors suggested that postoperative alterations in bile acid recirculation may contribute to improved glucose and lipid metabolism after RYGB [79].

\section{Discussion}

Prompt improvement in glycaemic control after RYGB surgery, measurable just a few days postoperatively, is a clinical reality $[3,8]$. Understanding the mechanisms behind this remarkable improvement in glucose metabolism may 
lead to a better understanding of the pathophysiology of type 2 diabetes and, hence, the identification of new drug targets and/or improved surgical techniques. In this article we have reviewed a large number of RYGB-related pathophysiological studies and, taken together, two main mecha- nisms seem to be responsible for the improvement in glycaemic control after RYGB: (1) an early increase in insulin sensitivity in the liver and later in skeletal muscle, and (2) improved beta cell function associated with an exaggerated postprandial GLP-1 secretion (Fig. 2).
Fig. 2 a Mechanisms responsible for the early improvement in glycaemic control after Roux-en-Y gastric bypass. b Mechanisms responsible for the sustained improvement in glycaemic control after Roux-en-Y gastric bypass. OXM, oxyntomodulin a

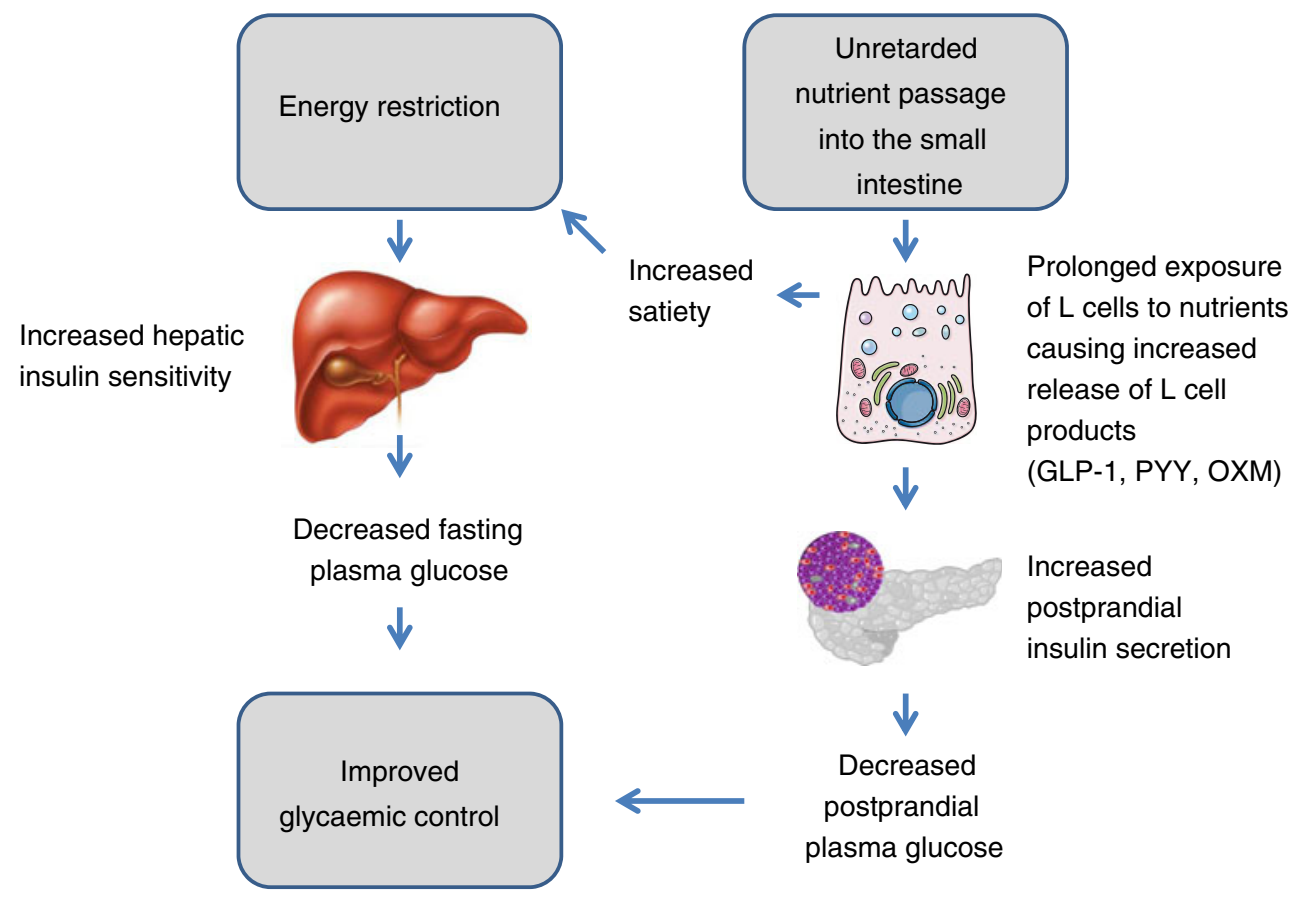

b

Long-term effects (months to years)

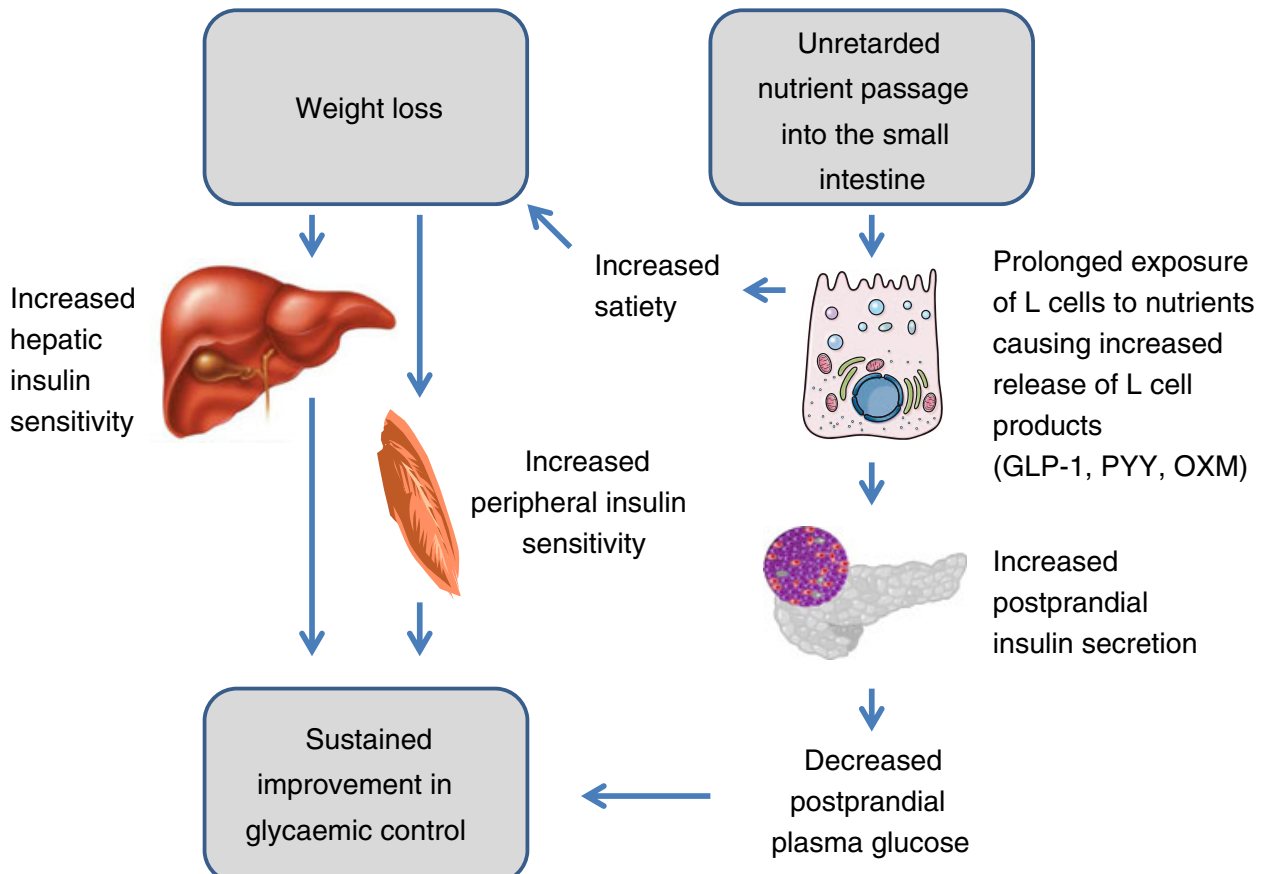


The early improvement in hepatic insulin sensitivity, demonstrated by the significant and consistent reduction in HOMA-IR during the first postoperative week, but yet to be conclusively confirmed using more specific clamp and tracer techniques, could be explained by postoperative energy restriction, as described above. Obese patients undergoing other forms of surgery do not experience a similar improvement in glycaemic control, but, rather, a temporary deterioration in glucose tolerance, supposedly due to low-grade inflammation, high NEFA levels in response to fat mobilisation and surgical stress with the activation of cortisol, catecholamines, glucagon and growth hormone during the first days after surgery [80]. A study meticulously comparing changes in glycaemic control during the first 1-2 postoperative weeks in type 2 diabetes patients treated with either gastric bypass or other forms of abdominal surgery during identical feeding schedules would be of major interest.

Beta cell function also seems to improve early after RYGB, particularly in response to oral stimuli. This is seen by a down- and leftward shift in the postprandial glucose concentration curve after RYGB compared with a parallel downshift after energy restriction [33] or gastric banding [11], e.g. resulting in larger reductions in $2 \mathrm{~h}$ postprandial glucose value after RYGB. These changes in postprandial glucose tolerance after RYGB are related to an exaggerated postprandial insulin response, i.e. a brisk rise and higher peak concentration of insulin, which is in sharp contrast to the low and late insulin response profile characterising patients with type 2 diabetes before surgery. Note that the improvement in insulin secretion is already apparent during the first meal after RYGB [49].

It has been suggested that the enhanced insulin secretion after RYGB is caused by a factor released from the gut in response to the rapid passage of nutrients into the small intestine, the so-called hindgut hypothesis [3]. It is therefore interesting that the peripheral plasma GLP-1 responses to a meal, which increase 10- to 20-fold after RYGB, are closely associated with postprandial insulin secretion $[38,44,49$, 62]. It may be argued that these peripheral GLP-1 levels are not much higher than those observed during treatment with GLP-1 receptor analogues, but several lines of evidence support the notion that endogenous as opposed to exogenous GLP-1 may influence insulin secretion via mechanisms other than direct interaction with the beta cells. From animal studies, GLP-1 is known to activate afferent sensory neurones, as well as hypothalamic nuclei regulating glucose metabolism, and to reflexly stimulate pancreatic insulin secretion $[81,82]$. These sensory mechanisms are exposed to much higher local concentrations of endogenous GLP-1 [83]. Therefore, although postprandial peripheral GLP-1 concentrations are not much higher than those observed after the administration of therapeutic GLP-1 agonists, much higher intraintestinal and intraportal concentrations may explain why endogenous GLP-1 might be more effective than peripherally administered GLP-1. It is possible that the high portal GLP-1 concentrations might also have insulinindependent effects on glucose metabolism via neural reflexes, e.g. HGP [84]. Further support for the importance of GLP-1 for the improvement in glycaemic control comes from experimental surgery in both animals and humans involving ileal interposition, where a segment of ileum is interposed within the upper jejunum, thereby increasing the exposure of the $\mathrm{L}$ cells to ingested nutrients without bypassing the duodenum. In rats, the operation significantly improves glucose metabolism without weight loss and increases the secretion of GLP-1 and PYY [85, 86]. In humans, the procedure combined with sleeve gastrectomy induced improved insulin sensitivity and beta cell function [87] and consequently improved glycaemic control [88].

The dramatic effect of RYGB on postprandial glucose tolerance was highlighted in 2005, when Service et al described six postoperative cases of hyperinsulinaemic hypoglycaemia with apparent nesidioblastosis severe enough to require partial pancreatectomy to control the symptoms [89]. Later, other investigators found no change in beta cell mass in the same tissue specimens as compared with better matched controls [90]. The pathogenesis of this syndrome is not clarified, but an imbalance between improved insulin sensitivity and exaggerated GLP-1 responses resulting in an excessive postprandial insulin secretion might be partly responsible. Indeed, prevention of the exaggerated release of GLP-1 in a patient with severe postoperative hypoglycaemia by feeding through a gastrostomy catheter inserted in the gastric remnant was shown to prevent hypoglycaemia [48].

Whether exclusion of nutrients from the duodenum also contributes to the improvement in glucose tolerance after RYGB via an unknown factor has also been a point of considerable interest, the so-called foregut hypothesis [3]. This hypothesis is supported by an experimental design in Goto-Kakizaki rats in which duodenal-jejunal bypass that excludes nutrient passage through the duodenum is compared with gastrojejunostomy with intact duodenal nutrient passage [91]. In these animals, only duodenal-jejunal bypass results in a significant improvement in glucose metabolism, despite no difference in food intake, nutrient absorption or weight loss between the two operations. Studies in humans after duodenal-jejunal bypass also show improvements in glycaemic control with little or no weight loss [92-95]. Additional support for the hypothesis comes from experiments involving a duodenal-jejunal plastic sleeve, causing nutrients to move from the stomach to the jejunum without coming into contact with the duodenal mucosa, a procedure that also improves glucose tolerance in patients with type 2 diabetes [96-99]. Interestingly, changes in the secretion of gut 
hormones including GLP-1 are observed both after duodenaljejunal bypass and implantation of the plastic sleeve [95, 99].

In conclusion, we suggest that improvements in hepatic insulin sensitivity induced by energy restriction, which are appreciable only a few days after the operation, and an exaggerated GLP-1 response, inducing a normalised or exaggerated insulin secretion profile after ingestion of a meal, explain the majority of the early improvement in glycaemic control that occurs after RYGB (Fig. 2a). The exaggerated GLP-1 response is likely to result from the unretarded passage of nutrients to more distal parts of the small intestine that have a higher density of $L$ cells. The interplay between the intestine-brain-islets of Langerhans demonstrated in rodents may also exist in humans and may also contribute to the improvement in glycaemic control, although documentation is needed. Thus, RYGB remains an inspiration in the search for new drug targets for the treatment of type 2 diabetes.

Duality of interest The authors declare that there is no duality of interest associated with this manuscript.

Contribution statement $\mathrm{CD}, \mathrm{NBJ}, \mathrm{KNBM}$ and SHJ have contributed to the drafting of the manuscript. All authors have contributed to the interpretation and analysis of the reviewed studies and have critically revised and given final approval of the present version of this manuscript.

\section{References}

1. Pournaras DJ, Aasheim ET, Sovik TT et al (2012) Effect of the definition of type II diabetes remission in the evaluation of bariatric surgery for metabolic disorders. Br J Surg 99:100-103

2. Sjostrom L, Lindroos AK, Peltonen M et al (2004) Lifestyle, diabetes, and cardiovascular risk factors 10 years after bariatric surgery. N Engl J Med 351:2683-2693

3. Pories WJ, Swanson MS, MacDonald KG et al (1995) Who would have thought it? An operation proves to be the most effective therapy for adult-onset diabetes mellitus. Ann Surg 222:339-350

4. Fried M, Ribaric G, Buchwald JN, Svacina S, Dolezalova K, Scopinaro N (2010) Metabolic surgery for the treatment of type 2 diabetes in patients with $\mathrm{BMI}<35 \mathrm{~kg} / \mathrm{m}^{2}$ : an integrative review of early studies. Obes Surg 20:776-790

5. Rubino F, Kaplan LM, Schauer PR, Cummings DE (2010) The Diabetes Surgery Summit consensus conference: recommendations for the evaluation and use of gastrointestinal surgery to treat type 2 diabetes mellitus. Ann Surg 251:399-405

6. Sjostrom L, Narbro K, Sjostrom CD et al (2007) Effects of bariatric surgery on mortality in Swedish obese subjects. N Engl J Med 357:741-752

7. Buchwald H, Estok R, Fahrbach K, Banel D, Sledge I (2007) Trends in mortality in bariatric surgery: a systematic review and meta-analysis. Surgery 142:621-632

8. Buchwald H, Estok R, Fahrbach K et al (2009) Weight and type 2 diabetes after bariatric surgery: systematic review and metaanalysis. Am J Med 122:248-256

9. Buse JB, Caprio S, Cefalu WT et al (2009) How do we define cure of diabetes? Diabetes Care 32:2133-2135
10. Nannipieri M, Mari A, Anselmino M et al (2011) The role of beta-cell function and insulin sensitivity in the remission of type 2 diabetes after gastric bypass surgery. J Clin Endocrinol Metab 96: E1372-E1379

11. Kashyap SR, Daud S, Kelly KR et al (2010) Acute effects of gastric bypass versus gastric restrictive surgery on beta-cell function and insulinotropic hormones in severely obese patients with type 2 diabetes. Int J Obes (Lond) 34:462-471

12. Navaneethan SD, Kelly KR, Sabbagh F, Schauer PR, Kirwan JP, Kashyap SR (2010) Urinary albumin excretion, HMW adiponectin, and insulin sensitivity in type 2 diabetic patients undergoing bariatric surgery. Obes Surg 20:308-315

13. Rodieux F, Giusti V, D’Alessio DA, Suter M, Tappy L (2008) Effects of gastric bypass and gastric banding on glucose kinetics and gut hormone release. Obesity (Silver Spring) 16:298-305

14. Falkén Y, Hellstrom PM, Holst JJ, Näslund E (2011) Changes in glucose homeostasis after Roux-en-Y gastric bypass surgery for obesity at day three, two months, and one year after surgery: role of gut peptides. J Clin Endocrinol Metab 96:2227-2235

15. Usinger L, Hansen KB, Kristiansen VB, Larsen S, Holst JJ, Knop FK (2011) Gastric emptying of orally administered glucose solutions and incretin hormone responses are unaffected by laparoscopic adjustable gastric banding. Obes Surg 21:625-632

16. Muscelli E, Mingrone G, Camastra S et al (2005) Differential effect of weight loss on insulin resistance in surgically treated obese patients. Am J Med 118:51-57

17. Pereira JA, Lazarin MA, Pareja JC, de Souza A, Muscelli E (2003) Insulin resistance in nondiabetic morbidly obese patients: effect of bariatric surgery. Obes Res 11:1495-1501

18. Fabbrini E, Tamboli RA, Magkos F et al (2010) Surgical removal of omental fat does not improve insulin sensitivity and cardiovascular risk factors in obese adults. Gastroenterology 139:448-455

19. Campos GM, Rabl C, Peeva S et al (2010) Improvement in peripheral glucose uptake after gastric bypass surgery is observed only after substantial weight loss has occurred and correlates with the magnitude of weight lost. J Gastrointest Surg 14:15-23

20. Camastra S, Gastaldelli A, Mari A et al (2011) Early and longer term effects of gastric bypass surgery on tissue-specific insulin sensitivity and beta cell function in morbidly obese patients with and without type 2 diabetes. Diabetologia 54:2093-2102

21. Promintzer-Schifferl M, Prager G, Anderwald C et al (2011) Effects of gastric bypass surgery on insulin resistance and insulin secretion in nondiabetic obese patients. Obesity (Silver Spring) 19:1420-1426

22. Gastaldi G, Russell A, Golay A et al (2007) Upregulation of peroxisome proliferator-activated receptor gamma coactivator gene $(P G C 1 A)$ during weight loss is related to insulin sensitivity but not to energy expenditure. Diabetologia 50:2348-2355

23. Friedman JE, Dohm GL, Leggett-Frazier N et al (1992) Restoration of insulin responsiveness in skeletal muscle of morbidly obese patients after weight loss. Effect on muscle glucose transport and glucose transporter GLUT4. J Clin Invest 89:701-705

24. Burstein R, Epstein Y, Charuzi I, Suessholz A, Karnieli E, Shapiro Y (1995) Glucose utilization in morbidly obese subjects before and after weight loss by gastric bypass operation. Int $\mathrm{J}$ Obes Relat Metab Disord 19:558-561

25. Lin E, Davis SS, Srinivasan J, Sweeney JF et al (2009) Dual mechanism for type-2 diabetes resolution after Roux-en-Y gastric bypass. Am Surg 75:498-502

26. Lin E, Phillips LS, Ziegler TR et al (2007) Increases in adiponectin predict improved liver, but not peripheral, insulin sensitivity in severely obese women during weight loss. Diabetes 56:735-742

27. Gletsu N, Lin E, Khaitan L et al (2005) Changes in C-reactive protein predict insulin sensitivity in severely obese individuals after weight loss surgery. J Gastrointest Surg 9:1119-1126

28. Pender C, Goldfine ID, Tanner CJ et al (2004) Muscle insulin receptor concentrations in obese patients post bariatric surgery: 
relationship to hyperinsulinemia. Int J Obes Relat Metab Disord 28:363-369

29. Geloneze B, Tambascia MA, Pareja JC, Repetto EM, Magna LA (2001) The insulin tolerance test in morbidly obese patients undergoing bariatric surgery. Obes Res 9:763-769

30. Garcia-Fuentes E, Garcia-Almeida JM, Garcia-Arnes J et al (2006) Morbidly obese individuals with impaired fasting glucose have a specific pattern of insulin secretion and sensitivity: effect of weight loss after bariatric surgery. Obes Surg 16:1179-1188

31. Klein S, Mittendorfer B, Eagon JC et al (2006) Gastric bypass surgery improves metabolic and hepatic abnormalities associated with nonalcoholic fatty liver disease. Gastroenterology 130:1564 1572

32. Isbell JM, Tamboli RA, Hansen EN et al (2010) The importance of caloric restriction in the early improvements in insulin sensitivity after Roux-en-Y gastric bypass surgery. Diabetes Care 33:1438-1442

33. Laferrere B, Teixeira J, McGinty J et al (2008) Effect of weight loss by gastric bypass surgery versus hypocaloric diet on glucose and incretin levels in patients with type 2 diabetes. J Clin Endocrinol Metab 93:2479-2485

34. Swarbrick MM, Stanhope KL, Austrheim-Smith IT et al (2008) Longitudinal changes in pancreatic and adipocyte hormones following Roux-en-Y gastric bypass surgery. Diabetologia 51:19011911

35. Korner J, Inabnet W, Febres G et al (2009) Prospective study of gut hormone and metabolic changes after adjustable gastric banding and Roux-en-Y gastric bypass. Int J Obes (Lond) 33:786-795

36. Pournaras DJ, Osborne A, Hawkins SC et al (2010) Remission of type 2 diabetes after gastric bypass and banding: mechanisms and 2 year outcomes. Ann Surg 252:966-971

37. Foo J, Krebs J, Hayes MT et al (2011) Studies in insulin resistance following very low calorie diet and/or gastric bypass surgery. Obes Surg 21:1914-1920

38. Umeda LM, Silva EA, Carneiro G, Arasaki CH, Geloneze B, Zanella MT (2011) Early improvement in glycemic control after bariatric surgery and its relationships with insulin, GLP-1, and glucagon secretion in type 2 diabetic patients. Obes Surg 21:896901

39. Lima MM, Pareja JC, Alegre SM et al (2010) Acute effect of Roux-en-Y gastric bypass on whole-body insulin sensitivity: a study with the euglycemic-hyperinsulinemic clamp. J Clin Endocrinol Metab 95:3871-3875

40. Dunn JP, Abumrad NN, Breitman I et al (2011) Hepatic and peripheral insulin sensitivity and diabetes remission at 1 month after Roux-en-Y gastric bypass surgery in patients randomized to omentectomy. Diabetes Care 35:137-142

41. Kirk E, Reeds DN, Finck BN, Mayurranjan SM, Patterson BW, Klein S (2009) Dietary fat and carbohydrates differentially alter insulin sensitivity during caloric restriction. Gastroenterology 136:1552-1560

42. Lim EL, Hollingsworth KG, Aribasale B, Chen MJ, Mathers JC, Taylor R (2011) Reversal of type 2 diabetes is associated with decrease in pancreas and liver fat levels. Diabetologia 54:25062514

43. Borg CM, Le Roux CW, Ghatei MA, Bloom SR, Patel AG, Aylwin SJ (2006) Progressive rise in gut hormone levels after Roux-en-Y gastric bypass suggests gut adaptation and explains altered satiety. Br J Surg 93:210-215

44. Laferrere B, Heshka S, Wang K et al (2007) Incretin levels and effect are markedly enhanced 1 month after Roux-en-Y gastric bypass surgery in obese patients with type 2 diabetes. Diabetes Care 30:1709-1716

45. Korner J, Bessler M, Cirilo LJ et al (2005) Effects of Roux-en-Y gastric bypass surgery on fasting and postprandial concentrations of plasma ghrelin, peptide YY, and insulin. J Clin Endocrinol Metab 90:359-365

46. Goldfine AB, Mun EC, Devine E et al (2007) Patients with neuroglycopenia after gastric bypass surgery have exaggerated incretin and insulin secretory responses to a mixed meal. J Clin Endocrinol Metab 92:4678-4685

47. Korner J, Bessler M, Inabnet W, Taveras C, Holst JJ (2007) Exaggerated glucagon-like peptide-1 and blunted glucosedependent insulinotropic peptide secretion are associated with Roux-en-Y gastric bypass but not adjustable gastric banding. Surg Obes Relat Dis 3:597-601

48. McLaughlin T, Peck M, Holst J, Deacon C (2010) Reversible hyperinsulinemic hypoglycemia after gastric bypass: a consequence of altered nutrient delivery. J Clin Endocrinol Metab 95:1851-1855

49. Dirksen C, Hansen DL, Madsbad S et al (2010) Postprandial diabetic glucose tolerance is normalized by gastric bypass feeding as opposed to gastric feeding and is associated with exaggerated GLP-1 secretion: a case report. Diabetes Care 33:375-377

50. Le Roux CW, Aylwin SJ, Batterham RL et al (2006) Gut hormone profiles following bariatric surgery favor an anorectic state, facilitate weight loss, and improve metabolic parameters. Ann Surg 243:108-114

51. Hofso D, Jenssen T, Bollerslev J et al (2011) Beta cell function after weight loss: a clinical trial comparing gastric bypass surgery and intensive lifestyle intervention. Eur J Endocrinol 164:231238

52. Reed MA, Pories WJ, Chapman W et al (2011) Roux-en-Y gastric bypass corrects hyperinsulinemia implications for the remission of type 2 diabetes. J Clin Endocrinol Metab 96:2525-2531

53. Hansen EN, Tamboli RA, Isbell JM et al (2011) Role of the foregut in the early improvement in glucose tolerance and insulin sensitivity following Roux-en-Y gastric bypass surgery. Am J Physiol Gastrointest Liver Physiol 300:G795-G802

54. Jorgensen NB, Dirksen C, Holst JJ, Madsbad S (2011) Gastric bypass and duodenal and gastric feeding: a comment to Hansen et al. Am J Physiol Gastrointest Liver Physiol 301:G938-G939

55. Morinigo R, Lacy AM, Casamitjana R, Delgado S, Gomis R, Vidal J (2006) GLP-1 and changes in glucose tolerance following gastric bypass surgery in morbidly obese subjects. Obes Surg 16:1594-1601

56. Lin E, Liang Z, Frediani $J$ et al (2010) Improvement in $\beta$-cell function in patients with normal and hyperglycemia following Roux-en-Y gastric bypass surgery. Am J Physiol Endocrinol Metab 299:E706-E712

57. Holst JJ (2011) Postprandial insulin secretion after gastric bypass surgery: the role of glucagon-like peptide 1. Diabetes 60:22032205

58. Rubino F, Gagner M, Gentileschi P et al (2004) The early effect of the Roux-en-Y gastric bypass on hormones involved in body weight regulation and glucose metabolism. Ann Surg 240:236242

59. Beckman LM, Beckman TR, Earthman CP (2010) Changes in gastrointestinal hormones and leptin after Roux-en-Y gastric bypass procedure: a review. J Am Diet Assoc 110:571-584

60. de Carvalho CP, Marin DM, de Souza AL et al (2009) GLP-1 and adiponectin: effect of weight loss after dietary restriction and gastric bypass in morbidly obese patients with normal and abnormal glucose metabolism. Obes Surg 19:313-320

61. Holdstock C, Zethelius B, Sundbom M, Karlsson FA, Eden EB (2008) Postprandial changes in gut regulatory peptides in gastric bypass patients. Int J Obes (Lond) 32:1640-1646

62. Salehi M, Prigeon RL, D'Alessio DA (2011) Gastric bypass surgery enhances glucagon-like peptide 1-stimulated postprandial insulin secretion in humans. Diabetes 60:2308-2314 
63. Morinigo R, Moize V, Musri M et al (2006) Glucagon-like peptide-1, peptide YY, hunger, and satiety after gastric bypass surgery in morbidly obese subjects. J Clin Endocrinol Metab 91:1735-1740

64. Morinigo R, Vidal J, Lacy AM, Delgado S, Casamitjana R, Gomis R (2008) Circulating peptide YY, weight loss, and glucose homeostasis after gastric bypass surgery in morbidly obese subjects. Ann Surg 247:270-275

65. Laferrere B, Swerdlow N, Bawa B et al (2010) Rise of oxyntomodulin in response to oral glucose after gastric bypass surgery in patients with type 2 diabetes. J Clin Endocrinol Metab 95:4072-4076

66. Holst JJ (2007) The physiology of glucagon-like peptide 1. Physiol Rev 87:1409-1439

67. Cummings DE, Weigle DS, Frayo RS et al (2002) Plasma ghrelin levels after diet-induced weight loss or gastric bypass surgery. N Engl J Med 346:1623-1630

68. Martins C, Kjelstrup L, Mostad IL, Kulseng B (2011) Impact of sustained weight loss achieved through Roux-en-Y gastric bypass or a lifestyle intervention on ghrelin, obestatin, and ghrelin/obestatin ratio in morbidly obese patients. Obes Surg 21:751-758

69. Olbers T, Bjorkman S, Lindroos A et al (2006) Body composition, dietary intake, and energy expenditure after laparoscopic Roux-en-Y gastric bypass and laparoscopic vertical banded gastroplasty: a randomized clinical trial. Ann Surg 244:715-722

70. Tamboli RA, Hossain HA, Marks PA et al (2010) Body composition and energy metabolism following Roux-en-Y gastric bypass surgery. Obesity (Silver Spring) 18:1718-1724

71. Miller GD, Carr JJ, Fernandez AZ (2011) Regional fat changes following weight reduction from laparoscopic Roux-en-Y gastric bypass surgery. Diabetes Obes Metab 13:189-192

72. Pardina E, Lecube A, Llamas R et al (2009) Lipoprotein lipase but not hormone-sensitive lipase activities achieve normality after surgically induced weight loss in morbidly obese patients. Obes Surg 19:1150-1158

73. Faraj M, Jones P, Sniderman AD, Cianflone K (2001) Enhanced dietary fat clearance in postobese women. J Lipid Res 42:571-580

74. Curry TB, Roberts SK, Basu R et al (2011) Gastric bypass surgery is associated with near-normal insulin suppression of lipolysis in nondiabetic individuals. Am J Physiol Endocrinol Metab 300:E746-E751

75. Faraj M, Havel PJ, Phelis S, Blank D, Sniderman AD, Cianflone K (2003) Plasma acylation-stimulating protein, adiponectin, leptin, and ghrelin before and after weight loss induced by gastric bypass surgery in morbidly obese subjects. J Clin Endocrinol Metab 88:1594-1602

76. Swarbrick MM, Austrheim-Smith IT, Stanhope KL et al (2006) Circulating concentrations of high-molecular-weight adiponectin are increased following Roux-en-Y gastric bypass surgery. Diabetologia 49:2552-2558

77. Butner KL, Nickols-Richardson SM, Clark SF, Ramp WK, Herbert WG (2010) A review of weight loss following Roux-en-Y gastric bypass vs restrictive bariatric surgery: impact on adiponectin and insulin. Obes Surg 20:559-568

78. Whitson BA, Leslie DB, Kellogg TA et al (2007) Adipokine response in diabetics and nondiabetics following the Roux-en-Y gastric bypass: a preliminary study. J Surg Res 142:295-300

79. Patti ME, Houten SM, Bianco AC et al (2009) Serum bile acids are higher in humans with prior gastric bypass: potential contribution to improved glucose and lipid metabolism. Obesity (Silver Spring) 17:1671-1677

80. Thorell A, Nygren J, Ljungqvist O (1999) Insulin resistance: a marker of surgical stress. Curr Opin Clin Nutr Metab Care 2:69-78

81. Nakabayashi H, Nishizawa M, Nakagawa A, Takeda R, Niijima A (1996) Vagal hepatopancreatic reflex effect evoked by intraportal appearance of tGLP-1. Am J Physiol 271:E808-E813
82. Balkan B, Li X (2000) Portal GLP-1 administration in rats augments the insulin response to glucose via neuronal mechanisms. Am J Physiol Regul Integr Comp Physiol 279:R1449-R1454

83. Hjøllund KR, Deacon CF, Holst JJ (2011) Dipeptidyl peptidase-4 inhibition increases portal concentrations of intact glucagon-like peptide-1 (GLP-1) to a greater extent than peripheral concentrations in anaesthetised pigs. Diabetologia 54:2206-2208

84. Dardevet D, Moore MC, Neal D, DiCostanzo CA, Snead W, Cherrington AD (2004) Insulin-independent effects of GLP-1 on canine liver glucose metabolism: duration of infusion and involvement of hepatoportal region. Am J Physiol Endocrinol Metab 287:E75-E81

85. Strader AD, Clausen TR, Goodin SZ, Wendt D (2009) Ileal interposition improves glucose tolerance in low dose streptozotocintreated diabetic and euglycemic rats. Obes Surg 19:96-104

86. Boza C, Munoz R, Yung E, Milone L, Gagner M (2011) Sleeve gastrectomy with ileal transposition (SGIT) induces a significant weight loss and diabetes improvement without exclusion of the proximal intestine. J Gastrointest Surg 15:928-934

87. De Paula AL, Stival AR, Halpern A et al (2011) Improvement in insulin sensitivity and beta-cell function following ileal interposition with sleeve gastrectomy in type 2 diabetic patients: potential mechanisms. J Gastrointest Surg 15:1344-1353

88. Tinoco A, El-Kadre L, Aquiar L, Tinoco R, Savassi-Rocha P (2011) Short-term and mid-term control of type 2 diabetes mellitus by laparoscopic sleeve gastrectomy with ileal interposition. World J Surg 35:2238-2244

89. Service GJ, Thompson GB, Service FJ, Andrews JC, CollazoClavell ML, Lloyd RV (2005) Hyperinsulinemic hypoglycemia with nesidioblastosis after gastric-bypass surgery. N Engl J Med 353:249-254

90. Meier JJ, Butler AE, Galasso R, Butler PC (2006) Hyperinsulinemic hypoglycemia after gastric bypass surgery is not accompanied by islet hyperplasia or increased beta-cell turnover. Diabetes Care 29:1554-1559

91. Rubino F, Marescaux J (2004) Effect of duodenal-jejunal exclusion in a non-obese animal model of type 2 diabetes: a new perspective for an old disease. Ann Surg 239:1-11

92. Ramos AC, Galvao Neto MP et al (2009) Laparoscopic duodenal-jejunal exclusion in the treatment of type 2 diabetes mellitus in patients with $\mathrm{BMI}<30 \mathrm{~kg} / \mathrm{m}^{2}$ (LBMI). Obes Surg 19:307-312

93. Geloneze B, Geloneze SR, Fiori C et al (2009) Surgery for nonobese type 2 diabetic patients: an interventional study with duodenal-jejunal exclusion. Obes Surg 19:1077-1083

94. Cohen RV, Schiavon CA, Pinheiro JS, Correa JL, Rubino F (2007) Duodenal-jejunal bypass for the treatment of type 2 diabetes in patients with body mass index of $22-34 \mathrm{~kg} / \mathrm{m}^{2}$ : a report of 2 cases. Surg Obes Relat Dis 3:195-197

95. Lee HC, Kim MK, Kwon HS, Kim E, Song KH (2010) Early changes in incretin secretion after laparoscopic duodenal-jejunal bypass surgery in type 2 diabetic patients. Obes Surg 20:1530 1535

96. Rodriguez-Grunert L, Galvao Neto MP, Alamo M, Ramos AC, Baez PB, Tarnoff M (2008) First human experience with endoscopically delivered and retrieved duodenal-jejunal bypass sleeve. Surg Obes Relat Dis 4:55-59

97. Tarnoff M, Rodriguez L, Escalona A et al (2009) Open label, prospective, randomized controlled trial of an endoscopic duodenaljejunal bypass sleeve versus low calorie diet for pre-operative weight loss in bariatric surgery. Surg Endosc 23:650-656

98. Escalona A, Yanez R, Pimentel F et al (2010) Initial human experience with restrictive duodenal-jejunal bypass liner for treatment of morbid obesity. Surg Obes Relat Dis 6:126131 
99. de Jonge C, Verdam FJ, Rensen SS et al (2011) Endobarrier duodenal-jejunal bypass liner rapidly improves diabetes parameters paralleled by increased postprandial GLP-1 and PYY levels in obese type 2 diabetic patients. Diabetologia 54(suppl 1):S84, Abstract

100. Matthews DR, Hosker JP, Rudenski AS et al (1985) Homeostasis model assessment: insulin resistance and beta-cell function from fasting plasma glucose and insulin concentrations in man. Diabetologia 28:412-419

101. Matsuda M, DeFronzo RA (1999) Insulin sensitivity indices obtained from oral glucose tolerance testing: comparison with the euglycemic insulin clamp. Diabetes Care 22:14621470
102. Pacini G, Mari A (2003) Methods for clinical assessment of insulin sensitivity and beta-cell function. Best Pract Res Clin Endocrinol Metab 17:305-322

103. Mari A, Schmitz O, Gastaldelli A et al (2002) Meal and oral glucose tests for assessment of beta-cell function: modeling analysis in normal subjects. Am J Physiol Endocrinol Metab 283:E1159E1166

104. DeFronzo RA, Tobin JD, Andres R (1979) Glucose clamp technique: a method for quantifying insulin secretion and resistance. Am J Physiol 237:E214-E223

105. Kahn SE (2003) The relative contributions of insulin resistance and beta-cell dysfunction to the pathophysiology of type 2 diabetes. Diabetologia 46:3-19 